\title{
MISCELÁNEA
}

\section{LÉXICO E HISTORIA: NEOLOGISMOS EN EL ESPAÑOL DEL SIGLO XIV}

Cada palabra nueva que se incorpora a la lengua de una comunidad hablante -incluso si se trata de una voz que viene a sustituir a otra ya anticuada y sinónima - constituye un verdadero acontecimiento en el devenir humano, por cuanto comporta un modo también nuevo de entender la realidad, una ampliación del campo de conocimiento del hombre.

Lo que acabamos de decir implica que a través del léxico incorporado a la lengua de un país en un determinado período de tiempo, puede vislumbrarse cuáles fueron las necesidades de sus hombres en esa época, cuáles sus inquietudes, sus actividades y hasta sus relaciones con otros pueblos.

Tratar de poner en conexión el léxico y la historia es justamente el propósito de este trabajo, que va a tener como telón de fondo cronologico el siglo xIV y como material de estudio las palabras que presumiblemente se introdujeron en el español a lo largo de esta centuria, por muy variadas razones.

En su Diccionario Crítico Etimológico de la lengua Castellana ', Joan Corominas recoge 1.369 palabras documentadas por vez primera en el siglo XIV. Estas formas proceden de sesenta y siete fuentes, distribuidas

1 Madrid, Gredos, 1959, 4 vols. Citaremos siempre a partir de este momento DCELC. 
así: treinta y ocho obras de carácter literario, ocho glosarios e inventarios y veintiún documentos, en su mayor parte fueros y leyes ${ }^{2}$.

Lo que Corominas indica al afirmar que una palabra se documenta por vez primera en una fecha es que se recoge entonces en un documento escrito, no que ése sea el momento de su introducción en el idioma, hecho que ha podido producirse con muchos años, incluso siglos, de anticipación. Por eso, para nuestro propósito habremos de seleccionar, entre las voces que el DCELC nos ha proporcionado como documentadas en el siglo xIV - hasta donde ello nos sea posible- a las que presumiblemente entraron en la lengua en dicho siglo, y sólo a ellas, separándolas de las documentadas también en el XIV pero quizá introducidas mucho antes.

Tras realizar un estudio detallado del material inicial, hemos excluido de nuestro corpus 678 formas ya que, o bien las hemos documentado en textos anteriores ${ }^{3} 0$ tenemos razones para pensar que ya estaban en la lengua con anterioridad 4. Así, nuestra nómina queda reducida a 691 palabras, que muy bien pudieron introducirse en el siglo xIV y que constituirán, por tanto, el legado léxico de este siglo al español ${ }^{5}$.

Sabemos que tan absurdo sería prescindir del factor cultural importantísimo que es la lengua, para caracterizar una época, como tomar éste dato solamente, para sacar de él conclusiones extra-linguiísticas. Por eso, vamos a acercarnos cautelosamente al material disponible a fin de hacer una reflexión sobre por qué son estos neologismos y no otros los que se incorporan - si es que se incorporan- al léxico español en el siglo XIv.

2 En nuestra Tesis Doctoral, Datos para un estudio de las aportaciones léxicas del siglo XIV al Español, Universidad de Granada, 1978, inédita, explicitamos ampliamente cuáles son estas fuentes. Entre las de carácter literario más mencionadas citaremos el Libro de Buen Amor, La Gran Conquista de Ultramar, y la obra de don Juan Manuel; Los Glosarios de Palacio, El Escorial y Toledo son la fuente principal del apartado segundo; diversos documentos, como el Testamento de $\mathrm{Pe}$ dro el Cruel, Fueros de Cáceres y Zorita, de Vizcaya, y leyes (leyes de Toro, de Moros...) constituyen las fuentes citadas en tercer lugar.

$3 \mathrm{~V}$. en el resumen de nuestra tesis Datos para un estudio..., editado por la Universidad de Granada, Secretariado de publicaciones, 1980, págs. 7-32, el método seguido y las obras sobre las que se ha realizado la verificación, todas ellas de carácter literario (págs. 33-37).

4 V. ISABEL DE TORRES, op. cit., págs. 46-47. Justificamos allí por qué hemos excluido 299 formas, dado su carácter de patrimoniales.

3 Con Gregorio Salvador - «Incorporaciones léxicas en el español del siglo xvirI», página $11-$ pensamos que aestas cuestiones de cómputo de fechas están sometidas a constante revisión y -consiguientemente- esta nómina puede y debe ser revisada tan pronto como aparezca en un documento escrito alguna de las palabras que la integran*. 
Y el primer paso que vamos a dar para emprender este camino es la ordenación de los términos ateniéndonos al campo nocional al que pueden adscribirse.

Nos parece que las palabras que constituyen nuestro corpus son términos referidos a uno de estos campos:

A) La vida diaria.

B) La vida social.

C) La vida política, el gobierno y la organización de la sociedad.

D) La guerra, la vida militar y la navegación.

E) La moral, la vida religiosa y eclesiástica.

F) El comercio y la industria.

G) Términos jurídicos o en relación con la administración de la justicia.

H) Términos abstractos.

I) Cualidades, virtudes y defectos.

J) La vida cultural.

K) La flora, la fauna, los minerales y términos en relación con las plantas y los animales.

L) Frases hechas y elementos gramaticales.

Añadiremos un último apartado -el $\mathbf{M}$ ) - en el que englobaremos una serie de acciones, de verbos, que no sabemos dónde incluir, además de algunas palabras también de difícil clasificación.

Dentro de cada uno de estos apartados generales realizaremos una clasificación más concreta, de acuerdo con las posibilidades que la porción del léxico correspondiente nos ofrezca.

\section{A) LA VIDA DIARIA}

1. Condiciones atmosféricas y clima:

calma, escacha (escarcha), estación, fortuna, granizar, ventiscar.

2. Términos en relación con la construcción de la casa, el hábitat y los accidentes geográficos:

atajo, cabezo, callejuela, camaranchón, canchal, cañada, carril, casería, cerro ${ }^{6}$, costa, cumbrera, descampado, espadaña, matacán, mu-

6 Cerro, en el siglo xiv se documenta como 'lomo', 'espinazo de los animales' o bien como 'elevación de tierra', por eso lo incluimos en dos campos distintos, el A) y el K). 
rón, pasaje, poste, raudal, regacho, serranía, taranquera (o talanquera), tejado, ventana, vereda.

3. Términos que designan partes del cuerpo humano o relacionados con ellas:

barba, bozo, canilla, cañada ${ }^{7}$, jarrete, momia, muela.

4. Objetos materiales en relación con la casa o las labores domésticas: agujero, alforja, almohada, alombra (alfombra), altaba (aldaba), antorcha, antipara (antiparra), arcaz, banasto, bancal, banqueta, bola, cable, canasta, canastilla, cantón, cáscara, cistierna (cisterna), cofre, cofrecillo, copo, cordel, estropajo, faraón (farón), fardel, funda, gamellón, harnero, limadura, prendedero, redondel, retaco, rodilla, tabaque, tachón, tapón, terrón, tintero, torcida, venda.

5. Nombres de vasijas:

alhiara (aliara), bacia, bacina, carraço (alcarraza), cazo, dornillo, escalfador, jarro, odricillo.

6. Herramientas e instrumentos:

alesna (lezna), alfilel (alfiler), almádana (almádena), asador, azuela, broca, cama, devanadera, esposas, grillos, palmatoria, rascador, ratoneras, rejada, tarabilla.

7. Ropas, calzados y adornos:

albornoz, alcándora, alfarda, alhaite, capirote, cenefa, estival, faldón, farapo (harapo), formal, galocha, gaván (gabán), gaya, gorguera, havalloro (abalorio), joyel, jubón, lista, madrueñas (madreñas), pañal, pellón, pinta, polaina, sayo, tabardina, zamarro, zanco.

8. Alimentos:

alfeñique, arrope, calostro, candio (cande), cecial, confite, fiambre, fideo, gallofa, golloría (gollería), grasa, hormigos, lonja, mendrugo, papilla, roseta, sopa, tableta, talvina.

9. Términos relacionados con la salud y la Medicina:

buba cifaque, entecarse, lobanillo, picaraza, potra, romadizado, romadizarse, roncha, sanear.

7 Cariada se documenta en el siglo xIv bien como "caño por donde sale el líquido de la cañada, recipiente', o como 'médula'; por eso está incluida en dos apartados dentro del campo A). 
10. Objetos para jugar:

columpio, muñeca, sonaja.

11. Acciones relacionadas con la vida diaria y doméstica:

apagar, cepillar, espulgar, rallar, remendar, remoler, tiznar.

\section{B) LA VIDA SOCIAL}

1. Tipos sociales concretos:

beduino, echacuervos, gallofo, goliardo, moçuelo (mozuelo), paje, parapoco, rufián, trataconventos, vagabundo.

2. Términos que designan oficios:

acetrero, almuédano, amugronador, argentero, barquero, boyero, bracero, buhonero, campesino, cantadera, cantero, cerrajero, çurrador (zurrador), especiero, gaitero, jubetero, juglara, limosnero, maestresala, ovejero, pitoflero, sastre, templero, tizonador, tripero, vaqueriza, vaquero, verdugo, viñador, yeguarizo (yegüerizo).

3. Términos varios que designan realidades de la vida en sociedad (juegos, costumbre...):

burdel, buz, espico (hospicio), luto, mancebía, naipe, viaje.

C) La VIDA POLfTICA, BL GOBIERNO Y LA ORgaNización DE LA SOCIBDAD

1. Términos generales en relación con la política, el gobierno y la organización:

calendario, cañada, cargo, catálogo, debate, gobierno, nómina, rol.

2. Actividades relacionadas con el gobierno, la politica y la organización:

administrar, aliar, aportar, arbitrar, atajar, conceder, designar, empadronar, proponer, votar.

3. Gobernantes, cargos y títulos:

comunero, concejal, emir, mariscal, marqués, merindad, ministril, monarca, realenco (realengo). 


\section{D) LA VIDA MILITAR, LA GUERRA Y LA NAVEGACIÓN}

1. Términos y acciones relacionados con la guerra y con la actividad militar:

arrapar, artillero, astrago (estrago), avanguardia (vanguardia), bando, bladar, batallar, blandir, capitanía, devastar, enardecer, encarnizarse, policía, reguarda, rezaga.

2. Armas y objetos relacionados con la guerra y con la actividad militar:

aljaba, armamento, banderola, bisarma, botafuego, broquel, cañivete, divisa, estoque, frecha (flecha), gata, jinete, morteruelo, pólvora, puñal, vira, viratón, virote.

3. Habilidades en relación con la vida militar y la guerra: ardid, esgrima, jineta ${ }^{8}$.

4. Parte de la armadura: arnés, bacinete, cañillera (canillera), capacete, cimera, cota, guante, guardabrazo, quixote (quijote).

5. Términos relacionados con la navegación: cadozo, singlar, toaje.

\section{E) LA MORAL Y LA VIDA RELIGIOSA Y ECLESIÁstica}

1. Términos relacionados con la moral:

bellaquería, calumniar, disimular, embriaguez, enconar, estinto (instinto), expiriencia (experiencia), lujuriar, moral, mundificar, rencilla, roncería, ruindad, truhanería.

2. Términos relacionados con la vida religiosa y eclesid́stica: abismal, afiuziar (ahuciar), arrodillar, beato, beguina, bula, canonizar, capilla, conciencia, contemplativo, corvillo, cuenta, diablura, flagelar, indulgencia, lardero, menorete, perlación (prelación), prebenda, precepto.

8 Recogemos esta forma en «armas» y en «habilidades» porque en el siglo xIV se documenta por vez primera en dos acepciones 'lanza pequeña' y 'arte de mon. tar a caballo'. 


\section{F) EL COMBRCIO Y LA LITERATURA}

1. Acciones y términos relacionados en general con las actividades mercantil $e$ industrial:

abasto, alcaná, alheñar, caravana, escotar, fablicar (fabricar), fardage, gastar, industrioso, monipodio (monopolio), sisa, telar, tonel.

2. Productos:

adragea (gragea), bocaxin (bocací), oropel, tafetán, zarazas.

3. Monedas:

ardite, florín, tornés.

G) TÉrminos JURfDicos O EN RELACIÓN

CON LA ADMINISTRACIÓN DE LA JUSTICIA

altercar, amonestación, apelar, arrestar, baldón, baldonar, bastardo, cadahalso (cadalso), codicilio (codicilo), cohecho, comparar, compeler, concierto, confrontar, contestar, cotejar, definitivo, defraudar, delitable, delito, disposición, distinción, divulgar, dotar, enducir (inducir), equivalencia, excepción, faltar, fallar, incorporar, información, injuria, instancia, instruir, lasto, legar, libelar, libelo, mayorazgo, paterno, perpetrar, picota, principio, rato, repudiar, restar, traspaso, vínculo.

\section{H) Términos abstractos}

andadura, apretura, arbitrio, atención, ausencia, bramura, desabrimiento, desatiento, esprandor (esplendor), familiaridad, fealdad, inducción, ralea, razonamiento, realiza, recelo, rudeza, sino, trance, trueco, voltura.

\section{I) Cualidades, viRTudes Y DEFEctos}

activo, achacoso, afanoso, altanero, altivo, andariego, andorra, arbitrario, arisco, ascondido (escondido), baladí, barbudo, barrigudo, bastante, bisuejo (bisojo), boyante, cantioso (cuantioso), cervuno, 
contento, corajudo, cuidadoso, desgraciado, diligente, durante, encarnizado, esmaltado, espantable, estremo (extremo), follón, gangoso, garrido, gayo, guardadero, hazino (zaíno), infame, intolerable, invernizo, lerdo, lindo, malsín, marfuz, mellado, ordinario, pagadero, pago, pasadero, paviota, plomado, polvoroso, pródigo, profundo, ralo, receloso, roín (ruin), rudo, rugoso, sabido, solapado, tacaño, terrible, tuerto, ufano, vedijudo, zumiento.

\section{J) Vida CUltural}

1. Lengua y literatura:

aljamía, auto, conseja, librete, metrificar, novela.

2. La música:

atabal, baile, caño, flauta, gaita, motete, puntar, sonete, trova.

3. Términos en relación con disciplinas particulares: cábala, historiar, piromancia.

4. Otros términos relacionados con la cultura: bachiller, bezero (becerro), científico, imprenta, renglón.

K) FLora, fauna, Minerales Y términos RBLAcionados CON ANIMALES Y PLANTAS

1. Plantas:

ajenuz, alarguez, albaricoque, amárzaga (alharma), cañafístula, cañaheja, castañar, cecotrí (aplicado al aloe), ceñido, ciruelo, habarraz, herbizuela (hierbezuela), naranjo, penca, retama, romero, trébol.

2. Flores y frutos:

baya, carrazo, guinda, hamapol (amapola), naranja, piñón, toronja.

3. Verbos que designan acciones en relación con las plantas: desflorar, desgajar, desmochar, escardar, ortigar, rozar.

4. Otros términos relacionados con las plantas: almazaque, ambra (ámbar), garrancho, pulpa, tocón. 
5. Mamiferos:

blanchete, borrego, buco, búfalo, cochino, comadreja, fiera, garduña, mastín, osezno, potra ${ }^{9}$, ternera, turón.

6. Aves:

aguilocho (aguilucho), alcatraz, alfaneque, caudón (alcaudón), esmerejón, estruces (avestruces), flamenqo (flamenco), garceta, girifalte (gerifalte), golondrino, graja, lavanco (onavanco), martinete, neblí, pico, quebrantahuesos, sisón, tortolilla, zorzal.

7. Animales marinos:

albur, arenque, besugo, caçon (cazón), coral, espadarte, liza, merluça (merluza).

8. Insectos:

mariposa, tabarro.

9. Términos que designan partes del cuerpo de los animales: agalla, bispiello (obispillo), buche, cerro, cuajar.

10. Términos que designan acciones que hacen o pueden hacer los animales:

balido, erizar, gorjear, latido, mahullar (maullar), rabear, relincho, trotar, vuelo.

11. Caza y pesca:

almadraba, apiolar, errexaca (arrejaque), capirotada, liga, montería, pesca, sainete, salvajina, señuelo.

12. Otros términos en relación con los animales:

alcafar, alcafre, alcahaz, almohaza, aprisco, cárneo, domesticar, lobuno, mesta, trasquirón (trasquilón), xáquima (jáquima).

13. Términos que designan minerales:

aceche, atíncar, azabaya (azabache), azarcón, azófar, balaj, esmalte, guija, guijarro.

- Potra se recoge como 'yegua joven' y como 'hernia' en el siglo xIv, por eso la hemos incluido en dos campos distintos. 


\section{L) Frases hechas y ELEMENTOS GRAMATICALES}

abajo, despacio, quienquier, (traer a) rodo, (de) rondón.

M) En este apartado vamos a incluir:

1. Un conjunto de verbos que no hemos podido clasificar en ninguno de los campos mencionados hasta ahora.

De éstos algunos pueden referirse a acciones de la vida diaria y doméstica: colocar, retaçar (retazar), quizá alguno más.

Otros tienen un carácter expresivo: bambolear, barbotear. Los hay que se refieren a acciones específicamente humanas: abarraganarse, guiñar, rifar.

Los hay también que indican acciones que pueden ser realizadas por el hombre y los animales: espereçarse (esperezarse), cojear.

Además de estos verbos mencionados nos encontramos con un larguísimo etc. de los más variados campos que vamos a ofrecer a continuación ordenado por orden alfabético:

Abollar, acudir, afear, agitar, aguaitar, amedrentar, aojar, apegar, asir, aterir, atestar, cobijar, consistir, deleznarse, desatentar, desgarrar, desgastar, deslizar, embardurnar (embadurnar), embarrar, empachar, empalagar, engorrar, esmaltar, estribar, farpar (harpar), fundar, matizar, mellar, menear, orinecer, pararse, pasmar, remecer, repuntarse, resquebrar, resurgir, retornar, saltear, solapar, suplicar, topar, tornear, trabucar, trocar, variar.

2. Forman también este apartado un conjunto de nombres de difícil clasificación:

Aparejo, asomada, cosquillas, cuchillada, desmayo, dorso, espique, gargajo, manada, mormullo (murmullo), peso, patada, resoplo, revés, zancadilla.

Estos son los datos. Vamos ahora a intentar una interpretación.

A simple vista, con sólo contar las palabras agrupadas bajo cada epígrafe, puede observarse que son los apartados A) y K) de nuestra clasificación los que comprenden un mayor número de términos. Esto quiere decir que las voces referidas a la vida cotidiana y las relacionadas con la naturaleza - flora, fauna... - constituyen el mayor bloque de nuestra nómina. 
Junto a esto, hay también otro dato que nos ha llamado la atención poderosamente, es la exigüidad de formas que hemos podido agrupar bajo los epígrafes E) - moral, vida eclesiástica y religiosa- y J) - la vida cultural-

Y nos ha llamado sobre todo la atención esto último porque en nuestro material inicial había muchos términos de estos dos campos que, por haberlos documentado en textos del siglo xIII, hemos tenido que excluir de nuestra nómina definitiva.

Quizá la clave de esta última constatación - la falta de términos en los apartados E) y J) - hemos de buscarla en la historia de la cultura y de la lengua del siglo xIV.

El siglo XIII supuso un enorme despertar cultural en la Castilla medieval, en todos los terrenos. Es en este siglo cuando se produce la aparición y posterior consolidación de la primera poesía culta en romance; en él se crean las Universidades de Palencia, Salamanca y Valladolid; florece la arquitectura gótica, se desarrolla la educación, se crea la prosa romance y los habitantes de Castilla comienzan a sentir interés por las Cruzadas, un fenómeno europeo que no había dejado sentir su influjo en un reino excesivamente preocupado por asuntos internos.

Todo este renacer estaba motivado por «la expansión militar que trajo consigo aparejada la recuperación económica unida a la renovación de energías, autoconfianza y desarrollo de la educación» ${ }^{10} \mathrm{y}$, hay que decirlo también, impulsado por la obra gigantesca en el campo cultural de Alfonso X el Sabio.

Es precisamente el reinado de este monarca -1252-1284- la época que registra una mayor actividad científica y literaria.

A lo largo de estos años se va realizando la fijación interna de la lengua castellana, lográndose la nivelación linguística del reino y la fijación de las grafías, que quedan sólidamente establecidas hasta el siglo XVI ${ }^{11}$.

Los problemas fundamentales con los que se enfrentan Alfonso $\mathbf{X}$ y sus colaboradores en su intento de "flexibilizar» el castellano, para hacerlo capaz de expresar lo que hasta entonces se expresaba en latín, son:

10 A. D. Deyermond, Historia de la Literatura Española. La Edad Media, Barcelona, Ariel, 19763, pág. 108.

11 V. R. LAPESA Melgar, Historia de la Lengua Española, Madrid, Gredos, 1980s, capítulo 9. En lo que de ahora en adelante digamos sobre la lengua del siglo Xrv seguiremos siempre a este autor. 
1. El problema de conseguir una mayor agilidad, una coherencia lógica más grande en la articulación y desarrollo de los períodos oracionales.

2. El problema ocasionado por la insuficiencia léxica del castellano, que necesitaba nuevos términos para expresar nuevos conceptos contenidos en nuevos temas.

Para obviar esta segunda dificultad, justamente el aspecto que a nosotros nos interesa, la solución que se les ofrece es doble:

- O echar mano a formas presentadas de otras lenguas, casi siempre es el latín la lengua que presta.

- O crear palabras nuevas a partir de otras preexistentes.

Ambos procedimientos son usados satisfactoriamente por los autores de este siglo.

Naturalmente, la mayor parte de estos préstamos -cultismos tomados del latín en su gran mayoría- son términos referidos a las ciencias, las letras, la teología o la filosofía, que alcanza un gran auge con el conocimiento de Aristóteles a través de las traducciones de Averroes. Y esto por una razón clara: el latín había sido hasta el momento la lengua de cultura $y$, por tanto, los temas relacionados con la cultura no podían ser tratados en lengua vulgar sin recurrir al latín. Los términos tomados del latín son modificados mínimamente en su forma, para adaptarlos a la fonética del castellano, y explicados convenientemente, para que puedan ser entendidos por los no letrados: «dizen en latín tribus por linages».

Así pues, no es extraño que en el siglo xIv, las parcelas del léxico que corresponden a lo que hemos denominado ampliamente «vida cul. tural», se vean poco pobladas en lo que a neologismos se refiere, pues el siglo xIII legó al xiv un rico arsenal de estas palabras, quizá no poseído por el pueblo, pero, desde luego, presente en los textos de la época.

Por otra parte, el siglo XIII - también lo será el xIV - es un siglo de honda preocupación moral. Prueba de ello son los abundantísimos catecismos político-morales que por esta época se escriben o se traducen del árabe ${ }^{12}$.

12 Entre estas obras podemos mencionar Los Diez Mandamientos, el Bonium, Las Flores de Filosofia, Poridat de las Poridades y La Nobleza y Lealtad o Libro de los Doze Sabios. Sobre la importancia de estas obras pueden consultarse:

H. KNust, Mitteilungen aus dem Euskurial, Bibl. Litt., Vereins in Stuttgart, CXLI, Tuibingen, 1870; Llord A. KAstzN, Poridat de las Poridades, Madrid, Seminario de Estudios Medievales de la Universidad de Wisconsin, 1957. 
Estos catecismos son obras sin intención literaria las más de las veces y constituyen, en frase de Bustos Tovar, «la respuesta a una grave preocupación por la conducta del hombre que alcanzará su culminación en la obra de Alfonso X El Sabio» ${ }^{13}$.

Aunque estas obras sean, ciertamente, producto de una larga tradición que arranca de muchos años atrás, y se prolonga hasta el siglo XIV inclusive ${ }^{14}$, el siglo XIII $-y$ dentro de él los reinados de Fernando III y Alfonso $\mathrm{X}$ - representa el momento de mayor auge para la difusión de tratados de este tipo $y$, lógicamente, el léxico relacionado con el tema, de no existir ya en castellano, hubo de ser incorporado o creado, según los casos, en estos años, por lo cual, nuevamente, el siglo XIV recogió una herencia anterior, razón que justifica la falta de términos relacionados con la moral que hemos observado en nuestro corpus.

Si tenemos también en cuenta la abundancia de obras con temática religiosa o devota, desde Berceo hasta El libro de los tres Reyes de Oriente, pasando por la mayor parte de lo escrito con anterioridad al siglo XIV, podemos igualmente explicarnos por qué tampoco abundan entre los neologismos de este siglo las palabras de los campos «vida religiosa» y «vida eclesiástica».

Con esto nos parece que justificamos -podemos justificar- las carencias. Pero apuntábamos también que, junto a estas faltas llamativas, constatábamos algunas frecuencias notables en los campos del léxico relacionados con la vida diaria y la naturaleza.

En este caso vamos a recurrir a la historia de la literatura, ya que es muy probable que reflexionando sobre las fuentes de las que procede nuestro léxico podamos llegar a alguna conclusión.

Fundamentalmente - no exclusivamente- son las obras literarias la fuente de la que Corominas ha sacado el léxico que documenta por vez primera en el siglo XIV.

Y dentro de esas fuentes, el Libro de Buen Amor, del Arcipreste de Hita, es la obra más mencionada como primer texto. Nada menos que alrededor de 4.00 formas de nuestra nómina tienen como fecha de su primera documentación 1330, 1335 6 1343, que son las que Corominas

Para el léxico de estas obras en concreto, puede verse J. J. DB Bustos Tovar, *Notas para el léxico de la prosa didáctica del siglo XII», en Studia Hispanica in Honorem R. Lapesa, II, Gredos, 1974, pág. 149 y sigs.

13 J. J. DE Bustos Tovar, Contribución al estudio del cultismo léxico medieval, páginas 191-92.

14 Por ejemplo, vid. Las Flores de Filosofia, insertas en la Historia del Caba. llero Zifar (cito por J. J. De Bustos Tovar, Contribución a la historia..., pág. 192 ).

LXVI, 3.0-4.0. -9 
señala en su $B D E L C$ como datación para el $L$. de B. $A .{ }^{15}$; lo cual, teniendo en cuenta que nuestro corpus inicial constaba de 1.369 palabras, supone un 30 por 100 del total.

Es de todos bien conocido el estilo y el contenido de la obra de Juan Ruiz. Obra abierta, en la que se introducen, por primera vez en la literatura castellana, modismos y refranes; obra en la que se acumulan las palabras, huyendo de la concisión, con el fin de conseguir el máximo de expresividad, con un lenguaje colorista, espontáneo y jugoso.

Este libro constituye para algunos uno de «los documentos mejores para (...) la evocación de la vida en siglos tan remotos» ${ }^{16}$. Tanto es así que Menéndez y Pelayo afirma que muy poco o nada sabríamos de las costumbres del siglo xiv si no fuera por el $L$. de $B$. A.; afirmación ésta que repite Menéndez Pidal en Poesía Juglaresca y Juglares, en lo tocante a un punto concreto del vivir popular «las manifestaciones de esas gentes ocupadas en alegrar la vida por cortes y plazas públicas» ${ }^{17}$.

Juan Ruiz, el gran estilista del siglo xIv junto con don Juan Manuel, consigue esta evocación de la que hablamos utilizando un léxico intuitivo, vivencial, que tiñe de espontaneidad y popularismo incluso el lenguaje de la escolástica contenido en las partes doctrinales del mismo, dándonos siempre la sensación de que está describiendo el ambiente desde su propia experiencia personal ${ }^{18}$.

Teniendo en cuenta lo dicho hasta este momento, no es extraño $-y$ podemos comprobarlo viendo las características del léxico que se documenta por vez primera en este texto- no es extraño, decimos, que nos encontremos con esta abundancia de voces referidas a la vida de cada día, a las costumbres e incluso a la vida doméstica, dentro de nuestro corpus.

Más extraña nos ha parecido la abundancia de términos dentro del grupo K). Y nos ha extrañado porque a lo largo del siglo xiII nos encontramos, de una parte, con una gran corriente de literatura didáctico-moral, como ya hemos dicho, dentro de la cual es muy frecuente

15 Con estas abreviaturas me referiré siempre al Breve Diccionario Etimológico de la Lengua Castellana (BDELC) y al Libro de Buen Amor (L. de B. A.).

$16 \mathrm{~J}$. M. AguADo, Glosario sobre Juan Ruiz, poeta castellano del siglo XIV, Madrid, Espasa Calpe, 1929, pág. 202.

17 Ibidem.

18 V. Margherita MorReale, «Glosario parcial del libro de Buen Amor; palabras relacionadas por su posición en el verso*, en Homenaje. Estudios de Filología e Historia Literaria Lusohispanas e Iberoamericanas publicadas para celebrar el tercer lustro..., La Haya, Van Goor Zonen, 1966, págs. 391-448, especialmente las páginas 391-402. 
la utilización de animales como protagonistas, piénsese en el Libro de Calila e Dimna, por ejemplo.

Además, son también muy frecuentes los tratados de carácter científico -0 al menos pretendidamente científico- sobre los animales y sus enfermedades - Libro de los Caballos, albeitería alfonsí, o el Libro de las enfermedades de las aves de caza, probablemente del siglo XIII -y sobre las plantas.

Todo esto podría haber determinado una disminución sensible de neologismos en este campo, aunque es también cierto que en el siglo XIV se continúan ambas corrientes en la literatura, la didáctico-moral, y la científica ${ }^{19}$.

De todos modos, probablemente de haber hecho también nuestra verificación sobre textos no literarios, habríamos podido documentar no pocos de estos términos en el siglo xIII y los resultados habrían sido distintos.

Para terminar este capítulo queremos hacer unas observaciones sobre dos vocablos presentes en nuestra nómina. Nos referimos a templero o templario y a florín.

Del primero de ellos, de templario o templero - ambas formas son documentadas por primera vez en el siglo xIV por Corominas- diremos que nos ha sorprendido enormemente el que su primera documentación en la literatura castellana, $L$. de los Gatos, comienzo del siglo xIv, coincida prácticamente con la fecha de la extinción de esta orden militar, que, como se sabe, fue disuelta en 1311 por el Concilio de Vienne.

Florín es uno de los tres términos que designan monedas recogidas en nuestro corpus ${ }^{20}$. La presencia de estas palabras nos habla de la intensificación de las transacciones comerciales en el siglo xIV. Concretamente en Aragón, en 1346 se crea el florín de oro ${ }^{21}$ y solamente unos años más tarde, en 1374, ya encontramos documentada esta palabra en un inventario aragonés, con lo cual la documentación y la adopción del término - de origen italiano- son casi simultáneas.

19 Mencionaremos el Libro de Buen Amor, que contiene fábulas cuyos protagonistas son animales y algunos de los «exempla recogidos en la obra de don Juan Manuel; con respecto a los libros más o menos científicos, en el siglo xIv se escriben al menos dos tratados de cetrería, debidos a la pluma del Canciller Ayala -Libro de la Caza de las Aves, en el que se incorpora una traducción del Livro de Falcoaria, de Prdro Mrnino- y de don Juan Manuel -el Libro de Caza-, además del Libro de Montería, atribuido a Alfonso XI.

20 En la nómina primitiva habŕa dos términos más que designaban monedas: besante y cornado.

21 Vid. J. A. Garcta de Cortazar, Historia de España. La época Medieval, Madrid, Alianza Editorial, 19763, pág. 140. 
En resumen: el siglo xIv es el heredero directo de otro siglo -el xIII- época de una grandísima preocupación moral y de un gran resurgir cultural. Estos hechos condicionan el carácter de los neologismos que se incorporan o se crean en el siglo xrv.

Además, puesto que nuestro material es fundamental -aunque no exclusivamente- de procedencia literaria, se acusan también en el léxico que analizamos las corrientes literarias y las obras concretas que se escriben por estos ańos.

Volvemos a insistir en que los resultados habrian sido muy distintos si hubiéramos compulsado el material que nos proporcionó Corominas con otro tipo de textos.

ISABEL DE TORRBS RAMTREZ 